\title{
Call for papers for Sustainability and digitalization: a game changer? Possibilities, perils, pathways
}

(C) Springer Japan 2015

\section{Aims and scope}

In this special feature, we aim to cover two megatrends and their interaction: sustainability and digitalization.

The well-established concept of sustainability is confronted with a technological leap referred to as a 'digital revolution' that opens the chapter of the digital age we live in.

The overconsumption of natural resources and its harmful consequences threaten the basis of our existence and that of future generations (WCED 1987). However, the discourse and research have not achieved more sustainability and humans are still systematically failing to meet the conditions for sustainability that relate to the biosphere as well as human society (Johnston et al. 2007). Hence, scholars rightly observe a fundamental "sustainability gap" (Lubin and Esty 2014). Indeed, corporations, organizations, and individuals globally continue to add unsustainable activities to their behaviors.

Given the stagnation of sustainable development, the overall "sustainability gap" continues to be a major issue. Parallel to this development stands the increasing spread of digital technology in all areas of life. Information and communication (ICT) technology constitute our new "digital age" (Schmidt and Cohen 2013), encompassing a richness of soft- and hardware and linked processes. Such ICT and Big Data can help promote sustainability (Gijzen 2013; Hampton et al. 2013), because the societal complexity of the planetary nervous system is strongly connected and these systems may lead to cascading effects that increase vulnerability (Helbing 2012). Via a big data-driven "transnational sustainability agency" (Seele 2015) or a digital "global participatory platform", for instance, digitalization can help increase (strong) sustainability in the environmental, social and economic sphere (Helbing, 2012).

The reporting of sustainability activities of corporations serves as one of many examples of how digitalization can promote sustainability. In their reporting on sustainability activities, corporations rely on digital technology to communicate their agendas to the out- and inside. Through new software solutions such as the unified digital data repository XBRL, information is spread in a comparable, consistent, and reliable way (Seele 2014; Tschopp and Huefner 2014). That way, this technological development provides an accurate and credible picture of a company's contribution to sustainability, as it mirrors the company's sustainability actions. More transparency in reporting through technology helps stakeholders track developments in sustainability and aids govern corporate activities over the long run.

Digitalization, as in the example of Big Data, offers new possibilities and pathways of how to shape the future and research (Shah et al. 2015). The stored information enables the monitoring of how infectious diseases spread globally (Hay et al. 2013). Algorithmic capacities such as XBRL allow for data processing and analysis that open up unseen predictive capabilities and thus a "time-ontological shift" (Seele 2014). Hence, digitalization bears consequences for transparency and accountability which opens up entirely new ways to shape, monitor, and govern sustainability. In conclusion, both megatrends, sustainability and digitalization, impose major transitions on our world and how we picture it.

In this regard, sustainability science is the scientific way of gathering data to analyze pathways towards a (more) 
sustainable world, taking into account future generations. Given its transformative nature, sustainability is expected to adapt to the new possibilities and perils of the digital age. Whether and in how far this transformation through digitalization facilitates or impedes the development of a more sustainable world, however, is still unknown.

The proposed special feature-for the first time- -sheds light on the different possibilities, perils, and pathways the digital revolution might bring for sustainability and sustainability science. It intends to address the overall question: Is digitalization a game changer for sustainability and if so, in what ways?

The aim of the special feature is to become the primary reference that provides research agendas, theoretical advancements, rigorous case studies, methodological implications and empirical evidence concentrated on how digitalization transforms sustainability. Meanwhile, limitations and threats also need to be considered. This special feature aims to address these two megatrends broadly and invites publications from the array of disciplines covered in sustainability science.

\section{Targeted articles}

Little has been published so far on the game-changing potential of digitalization and sustainability.

This special feature welcomes theoretical, conceptual as well as rigorous empirical contributions that address implications for sustainability science. Potential topics include, but are by no means limited to:

- Empirical case studies where digitalization plays a major role for sustainability.

- Experimental studies of digital sustainability settings.

- Research addressing the link between digital media and sustainability.

- Digitalization, sustainability, and different actors.

- Theory advancement and conceptual models of digitalization and sustainability.

- Digitalization's role for sustainable development in a global governance perspective.

- Climate change, renewable energy, and the role of digitalization.

- Ecosystem and digitalization.

- The potential or impact of digitalization on sustainable landscapes.

- Eco-innovations and the role of digitalization.

\section{Important dates}

- 30 October 2015: Submission of abstracts to (both) guest editors (500 words excl. references).
- 15 November 2015: Communication about accepted abstracts.

- 29 February 2016: Submission of full manuscripts to guest editors.

- 30 June 2016: Communication of in—or-out decision of guest editors to authors.

- 30 August 2016: Submission of revised full manuscripts to sustainability science journal.

- End 2016-Early 2017: Planned publication of special feature.

\section{Guest editors}

Peter Seele, USI, University of Lugano/Switzerland, peter.seele@usi.ch.

Irina Lock, Technical University of Munich/Germany, irina.lock@tum.de.

\section{References}

Gijzen H (2013) Development: big data for a sustainable future. Nature 502:38

Hampton SE, Strasser CA, Tewksbury JJ, Gram WK, Budden AE, Batcheller AL, Duke CS, Porter JH (2013) Big data and the future of ecology. Front Ecol Environ 11(3):156-162

Hay SI, George DB, Moyes CL, Brownstein JS (2013) Big data opportunities for global infectious disease surveillance. PLoS med 10(4):e1001413

Helbing D (2012) The FuturICT knowledge accelerator towards a more resilient and sustainable future. In: Ball P (ed) Why society is a complex matter. Springer, Berlin, pp 55-60

Johnston P, Everard M, Santillo D, Robèrt K-H (2007) Reclaiming the definition of sustainability. Environ Sci Pollut Res 14(1):60-66

Lubin DA, Esty DC (2014) Bridging the sustainability gap. MITSloan Manag Rev, June 2014

Schmidt E, Cohen J (2013) The new digital age. Reshaping the future of people, nations and business. Knopf, New York

Seele P (2014). Unified Reporting: Integrating XBRL data repositories into sustainability reporting. 17th Environmental and Sustainability Management Accounting Network (EMAN): From Sustainability Reporting to Sustainability Management Control. EMAN 2014.4. ISBN: 9789056770006; doi: 10.13140/ 2.1.3311.5842

Seele P (2015). The Sustainability panopticon in the digital age. ECLC Working Paper 15/1

Shah DV, Cappella JN, Neuman WR (2015) Big data, digital media, and computational social science possibilities and perils. ANNALS Am Acad Political Social Sci 659(1):6-13

Tschopp D, Huefner RJ (2014) Comparing the evolution of CSR reporting to that of financial reporting. J Bus Ethics. doi:10.1007/ s10551-014-2054-6

WCED (World Commission on Environment and Development) (1987). Our common future. Aka. The Brundtland Report 